ISSN = 1980-993X - doi:10.4136/1980-993X
www.agro.unitau.br/ambi-agua
E-mail: ambi-agua@agro.unitau.br
Tel.: (12) 3625-4116

\title{
Qualidade dos recursos hídricos da Amazônia - Rio Tapajós: avaliação de caso em relação aos elementos químicos e parâmetros físico-químicos \\ (doi:10.4136/ambi-agua.88)
}

\author{
Rafaella Galvão Miranda ${ }^{1}$; Simone de Fátima Pinheiro Pereira ${ }^{1}$; Danila Teresa \\ Valeriano Alves ${ }^{1}$; Geiso Rafael Fonseca Oliveira ${ }^{1}$ \\ ${ }^{1}$ Laboratório de Química Analítica e Ambiental (LAQUANAM) - Universidade Federal do Pará \\ E-mail: rafaella.galvao@hotmail.com; simonefp@ufpa.br; danilavaleriano@yahoo.com.br; \\ geisorafael@ymail.com.br
}

\section{RESUMO}

O rio Tapajós é um dos principais rios do Estado do Pará, fazendo parte da Bacia Amazônica, a maior bacia hidrográfica do mundo, entretanto, o aumento populacional e o desenvolvimento da agropecuária na região tem gerado o aporte de contaminantes nesse importante rio da região. O objetivo deste trabalho foi avaliar a qualidade da água do rio Tapajós quanto à presença de metais e aos parâmetros físico-químicos, tendo como base a resolução 357-05 do CONAMA. Foram selecionadas sete estações de amostragem ao longo do rio, na camada superficial, intermediária e fundo no período de maior precipitação pluviométrica. Os elementos $\mathrm{Ca}, \mathrm{Mg}, \mathrm{Al}, \mathrm{Fe}, \mathrm{Ba}, \mathrm{Mn}, \mathrm{Sr}, \mathrm{Ti}, \mathrm{Ag}, \mathrm{Be}, \mathrm{Cd}, \mathrm{Co}, \mathrm{Cr}, \mathrm{Cu}, \mathrm{Mo}, \mathrm{Ni}$, $\mathrm{Pb}$ e $\mathrm{Zn}$ foram determinados usando a espectrometria de emissão atômica com plasma indutivamente acoplado (ICP-AES), o As foi determinado por ICP-AES com geração de hidretos, $\mathrm{Hg}$ foi determinado por absorção atômica com vapor frio e os parâmetros físicoquímicos foram avaliados usando diversas técnicas. Em quase todos os pontos os elementos $\mathrm{Al}$ e $\mathrm{Fe}$ se apresentaram em não conformidade com os valores permitidos pela legislação brasileira, com valores médios de $280,01 \pm 294,69 \mu \mathrm{g} / \mathrm{L}$ e $564,89 \pm 326,5 \mu \mathrm{g} / \mathrm{L}$, respectivamente. Foram observadas excelentes correlações entre $\mathrm{Ca}$ e $\mathrm{Mg}, \mathrm{Ca}$ e $\mathrm{Sr}, \mathrm{Mg}$ e $\mathrm{Sr}, \mathrm{Mn}$ e $\mathrm{Ba}, \mathrm{Sr}$ e OD e $\mathrm{Mg}$ e OD. O rio Tapajós apresentou níveis elevados de $\mathrm{Al}$ e Fe que comprometem a qualidade deste importante rio da Amazônia e podem causar problemas para a saúde da população.

Palavras-chave: metais pesados; Tapajós; Santarém; água.

\section{Quality of water resources in the Amazon region - Rio Tapajós: assessing the case for chemical elements and physical-chemical parameters}

\section{ABSTRACT}

The Tapajós river is the main river of the Pará State and part of the Amazon basin, the largest world river basin, however, the population growth and development of agriculture in the region has generated inputs of contaminants in this important river. The objective of this study was to evaluate the water quality of the Tapajós river in the presence of metals and physico-chemical parameters based on the CONAMA 357-05 resolution. Seven sampling stations were selected along the river in the surface, intermediate and bottom layers in low rainfall periods. The elements $\mathrm{Ca}, \mathrm{Mg}, \mathrm{Al}, \mathrm{Fe}, \mathrm{Ba}, \mathrm{Mn}, \mathrm{Sr}, \mathrm{Ti}, \mathrm{Ag}, \mathrm{Be}, \mathrm{Cd}, \mathrm{Co}, \mathrm{Cr}, \mathrm{Cu}, \mathrm{Mo}$, $\mathrm{Ni}, \mathrm{Pb}$ and $\mathrm{Zn}$ were determined using the inductively coupled plasma atomic emission spectrometry (ICP-AES). As was determined by ICP-AES with hydride generation, $\mathrm{Hg}$ was 
determined by cold vapor atomic absorption and the physico-chemical parameters were evaluated using various techniques. In almost all respects the elements $\mathrm{Al}$ and $\mathrm{Fe}$ are not presented in accordance with the values allowed by Brazilian legislation, with average values of $280.01 \pm 294.69 \mu \mathrm{g} / \mathrm{L}$ and $564.89 \pm 326.5 \mu \mathrm{g} / \mathrm{L}$, respectively. There were excellent correlations between $\mathrm{Ca}$ and $\mathrm{Mg}, \mathrm{Ca}$ and $\mathrm{Sr}, \mathrm{Mg}$ and $\mathrm{Sr}, \mathrm{Mn}$ and $\mathrm{Ba}, \mathrm{Sr}$ and $\mathrm{OD}, \mathrm{Mg}$ and OD. The Tapajós River showed high levels of $\mathrm{Al}$ and $\mathrm{Fe}$ that compromises the quality of this important river of the Amazon and can cause problems to the health of the population.

Keywords: heavy metals; Tapajós; Santarém; water.

\section{INTRODUÇÃO}

A humanidade, até algumas décadas atrás, tinha a água como um bem infinito e a capacidade de autodepuração dos corpos d'água também o era. Mas nas últimas décadas, o rápido desenvolvimento industrial, o aumento do número de habitantes e da produtividade agrícola trouxeram como consequência a preocupação com a qualidade e disponibilidade da água para consumo humano, devido à rápida degradação dos corpos d'água (Marques et al., 2007).

Segundo Hadlich e Scheibe (2007), a ocupação e uso do solo por atividades humanas alteram processos biológicos, físicos e químicos dos sistemas naturais. Alterações ocorridas em uma bacia hidrográfica podem ser avaliadas por meio do monitoramento da qualidade da água, pois, pelo ciclo hidrológico, as precipitações sobre as vertentes possibilitam o escoamento superficial e subsuperficial das águas, propiciando o transporte de poluentes para a rede de drenagem. Dessa forma, os rios integralizam consequências de diversos fenômenos ocorrentes na bacia.

O planejamento inadequado da urbanização na maioria das cidades brasileiras vem ocasionando alterações no ambiente que podem influenciar direta ou indiretamente na qualidade de vida da população. Esse processo provoca alterações nos ambientes, tais como: desmatamento, impermeabilização do solo, movimentos de terra, alteração da topografia, aterramentos de áreas baixas ou alagadas e a veiculação de poluentes. Em consequência, sob certas condições ambientais, as ocupações urbanas podem se tornar importantes fontes de poluição dos recursos hídricos (Göbel et. al., 2007; Chalmers et. al., 2007).

A bacia Amazônica, com aproximadamente $6.100 .000 \mathrm{~km}^{2}$ é a maior bacia hidrográfica do planeta. De dimensões continentais, essa bacia está situada na zona intertropical, recebendo precipitações médias anuais de $2460 \mathrm{~mm}$. A descarga líquida média é estimada em 209.000 $\mathrm{m}^{3} \cdot \mathrm{s}^{-1}$, seus principais afluentes são os rios Amazonas, Solimões, Negro, Madeira, Xingu, Trombetas e Tapajós (Abdo et al., 1997).

A poluição das águas é, principalmente, fruto de um conjunto de atividades humanas e os poluentes alcançam águas superficiais e subterrâneas de formas diversas. Esse aporte é arbitrariamente classificado como pontual e difuso, principalmente para efeito de legislação (Zimmerman et al., 2008). Em vista desse cenário, tem-se observado a crescente necessidade de se avaliar e monitorar as alterações ambientais e seus efeitos sobre os recursos hídricos, principalmente no que se refere à presença de metais pesados e aos parâmetros físicoquímicos. O monitoramento dos rios, como ferramenta de avaliação dos ecossistemas fluviais, tem fornecido subsídios para uma análise integrada da sua qualidade.

Segundo Förstner e Wittmann (1983), os metais chegam ao meio hídrico por meio de três vias principais: deposição de material particulado atmosférico, escoamento superficial da água da chuva após lavagem e lixiviação do solo e lançamento direto de despejos industriais e urbanos nos corpos de água. Os metais tóxicos são transportados principalmente pelas águas, sob duas formas físicas: as espécies dissolvidas e as espécies associadas às partículas sólidas. 
Os elementos químicos têm sido usados para caracterizar e avaliar problemas de contaminação relacionados com os corpos hídricos da Amazônia. Küchler et al. (2000) analisaram amostras de água do Rio Solimões e do Rio Negro e seus afluentes. As análises consistiram em medidas de $\mathrm{pH}$, condutividade, carbono orgânico (DOC) e metais que foram determinados por espectrometria de massas com fonte de ICP. Seyler e Boaventura (2001) realizaram um estudo sistemático de dissolução e transporte de metais traço $(\mathrm{V}, \mathrm{Cr}, \mathrm{Mn}, \mathrm{Co}$, $\mathrm{Cu}, \mathrm{Zn}, \mathrm{As}, \mathrm{Rb}, \mathrm{Sr}, \mathrm{Mo}, \mathrm{Cd}, \mathrm{Sb}, \mathrm{Cs}, \mathrm{Ba}, \mathrm{U})$ em material em suspensão nos grandes rios da Bacia Amazônica (rios Solimões, Negro, Purus, Madeira, Trombetas, Tapajós e Amazonas).

$\mathrm{Na}$ década de 80, a região amazônica, incluindo extensa área do rio Tapajós, sofreu intensa exploração do ouro, a amalgamação com mercúrio metálico era o processo utilizado na pré-concentração e extração do metal precioso. Como resultado, grandes quantidades de mercúrio foram lançadas nos principais rios e na atmosfera do ecossistema amazônico (Lacerda e Salomons, 1998; Malm, 1998 e Roulet et al., 2000).

As altas concentrações de mercúrio, encontradas no ecossistema amazônico foram, via de regra, atribuídas à mineração de ouro (Pfeiffer e Lacerda, 1988; Malm et al., 1990; Nriagu, 1992), à presença de solos com concentrações relativamente elevadas de mercúrio de origem natural (Roulet et al., 1998) e outras fontes. O mercúrio lançado indiscriminadamente no rio contaminou a biota aquática e a população que consumia peixes e água contaminada com o mercúrio (Akagi et al., 1995; Rodrigues et al., 1994; Harada et al., 2001 e Sa et al., 2006).

A proposta deste trabalho envolve a avaliação da qualidade dos recursos hídricos da Amazônia, particularmente do rio Tapajós, no entorno da cidade de Santarém, próximo da sua foz no rio Amazonas, tendo em vista os parâmetros físico-químicos e os elementos químicos.

\section{MATERIAL E MÉTODOS}

O município de Santarém está situado na microrregião do médio Amazonas, a 2²5'30" de latitude sul e $54^{\circ} 42^{\prime} 50^{\prime \prime}$ de longitude oeste (Figura 1), localizado na margem direita do rio Tapajós, na confluência com o rio Amazonas. Santarém possui cerca de 270.000 habitantes e uma área de unidade territorial de $22.887 \mathrm{~km}^{2}$, segundo dados estatísticos do IBGE (2009). Em Santarém, o aumento populacional levou a construção de núcleos habitacionais desordenados e sem saneamento básico. Esgotos sem nenhuma espécie de tratamento são lançados indiscriminadamente no rio e comprometem a saúde da população que utiliza a água para diversos fins.

O terminal graneleiro, de uma multinacional, construído em frente à cidade, tem como função a exportação de grãos da agricultura local e de outras regiões do país. Esse terminal recebe navios oriundos de vários países do mundo, que, involuntariamente, podem contaminar os recursos hídricos locais, uma vez que, é prática usual, o despejo das águas de lavagem dos porões que podem servir de transportes de poluentes orgânicos e inorgânicos e microorganismos. O comércio com outros municípios da região, feito por pequenas embarcações, também é uma fonte de contaminação, uma vez que lixo e dejetos dessas embarcações são jogados diretamente no rio Tapajós e permanecem acumulados em frente à orla da cidade. Outros pontos de lançamento de efluentes foram identificados e influenciaram a escolha das estações de amostragem.

Foram selecionadas sete estações de amostragem ao longo do rio Tapajós (Figura 1), no sentido da montante para jusante, na camada superficial, intermediária e fundo, no período de menor precipitação pluviométrica, os procedimentos adotados foram baseados no Guia de Coleta e Preservação de Amostras de Água da Companhia de Tecnologia de Saneamento Ambiental (CETESB, 1987). As estações foram escolhidas seguindo do centro da cidade, próxima ao terminal de carga de grãos até a periferia da cidade onde se observaram grandes lançamentos de efluentes. Foram usadas informações locais dos pontos de lançamento de 
efluentes para delimitar os pontos com base na carta náutica 4103B de Prainha a Costa do Ituqui, delimitados por referências terrestres e georeferenciadas por meio de um GPS (tabela 1) em intervalos regulares. Em uma única viagem a campo, 63 amostras ( 9 amostras de cada estação, 3 em cada profundidade) de água do rio Tapajós, foram coletadas com o auxílio de barco e frasco de coleta tipo Van Dorn, ao longo da orla da cidade de Santarém no período sazonal de maior pluviosidade (período chuvoso - mês de janeiro), o número de amostras foi estabelecido de acordo com a área delimitada no estudo e em função dos locais de lançamento de efluentes.

Após a coleta e antes do acondicionamento, procederam-se as medidas de oxigênio dissolvido, temperatura, $\mathrm{pH}$ e turbidez. As amostras para determinação de alcalinidade foram coletadas em frasco plástico, e o volume necessário foi de $200 \mathrm{~mL}$. As amostras não analisadas imediatamente foram preservadas sob refrigeração a $4^{\circ} \mathrm{C}$.

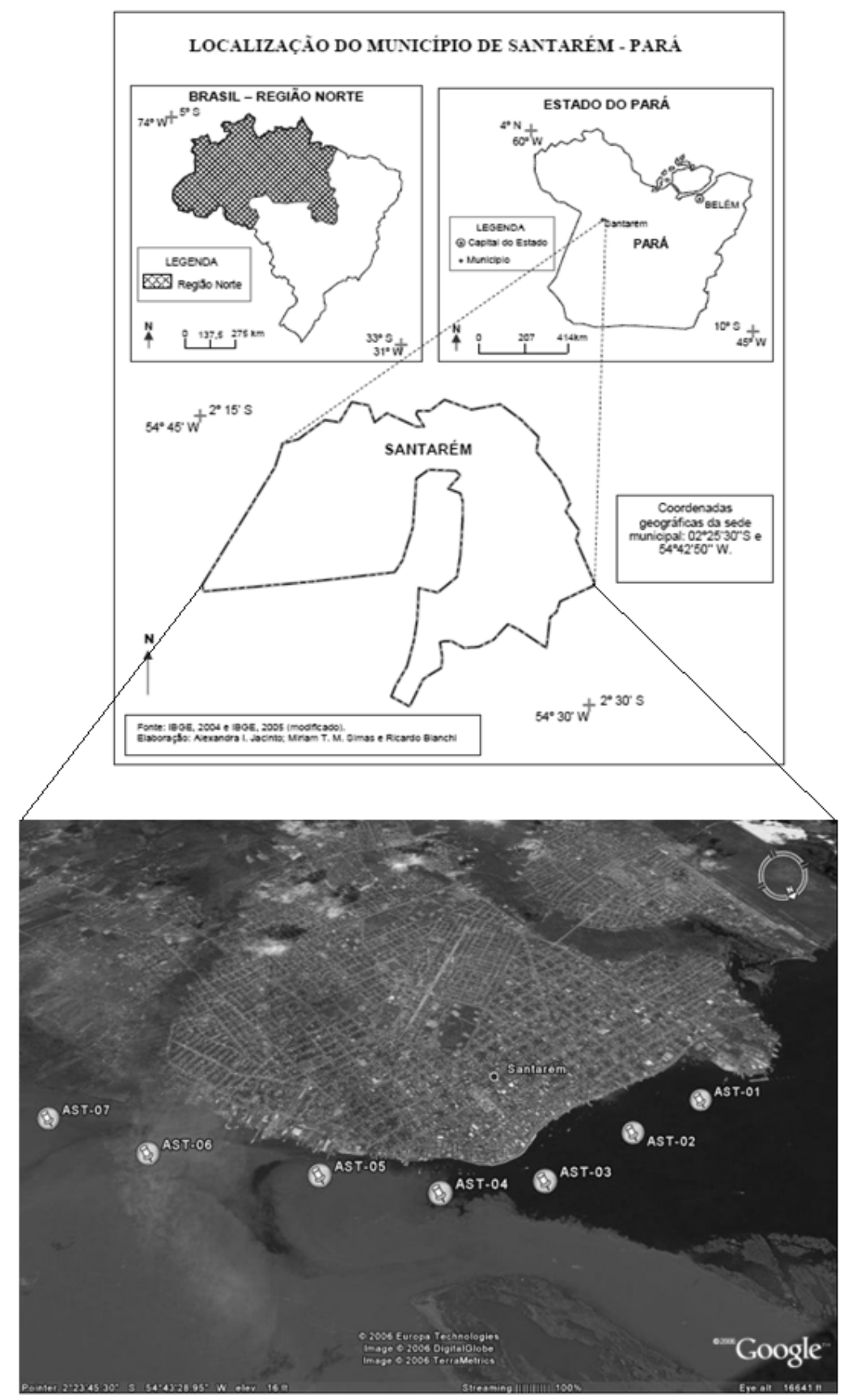

Figura 1. Localização do Município de Santarém, Pará,com pontos amostrais no rio Tapajós. 
MIRANDA, R. G.; PEREIRA, S. F. P.; ALVES, D. T. V.; OLIVEIRA, G. R. F. Qualidade dos recursos hídricos da Amazônia - Rio Tapajós: avaliação de caso em relação aos elementos químicos e parâmetros físico-químicos. Ambi-Agua, Taubaté, v. 4, n. 2, p. 75-92, 2009. (doi:10.4136/ambi-agua.88)

Para a análise dos metais solúveis, as amostras foram filtradas em filtro milipore $0,22 \mu \mathrm{m}$ que retem pequenas partículas, acidificadas com ácido nítrico até $\mathrm{pH} 2$ e encaminhadas para as análises dos elementos maiores, menores e traço por espectrometria de emissão atômica com plasma indutivamente acoplado (ICP-AES). O As foi determinado usando o ICP-AES com geração de hidretos e mercúrio foi analisado por espectrofotometria de absorção atômica com geração de vapor frio (CVAAS). Os métodos utilizados nos parâmetros físico-químicos e na análise dos elementos estão mostrados na tabela 2.

Tabela 1. Localização dos pontos amostrais no rio Tapajós.

\begin{tabular}{|c|c|c|c|}
\hline Pontos & Sul & Oeste & Descrição do ponto \\
\hline AST 01 & $02^{\circ} 24^{\prime} 52,40^{\prime \prime}$ & $54^{\circ} 43^{\prime} 52,60^{\prime}$ & $\begin{array}{l}\text { Ponto localizado no centro urbano de Santarém } \\
\text { próximo ao terminal Graneleiro CARGIL } \\
\text { sujeito a descargas de navios. }\end{array}$ \\
\hline AST 02 & $02^{\circ} 24^{\prime} 50,76^{\prime \prime}$ & $54^{\circ} 43^{\prime} 24,92^{\prime}$ & $\begin{array}{l}\text { Ponto localizado no centro urbano de Santarém } \\
\text { próximo à Praça Tiradentes sujeito a despejos } \\
\text { de esgotos domésticos. }\end{array}$ \\
\hline AST 03 & $02^{\circ} 24^{\prime} 47,03^{\prime \prime}$ & $54^{\circ} 42^{\prime} 51,04^{\prime}$, & $\begin{array}{l}\text { Ponto localizado no centro urbano de Santarém } \\
\text { próximo à Matriz sujeito a despejos de esgotos } \\
\text { domésticos e efluentes industriais e a descargas } \\
\text { de navios. }\end{array}$ \\
\hline AST 04 & $02^{\circ} 24^{\prime} 56,20^{\prime}$ & $54^{\circ} 42^{\prime} 22,00^{\prime}$ & $\begin{array}{l}\text { Ponto localizado no centro urbano de Santarém } \\
\text { próximo ao Museu João Fona sujeito a despejos } \\
\text { de esgotos domésticos e efluentes industriais. }\end{array}$ \\
\hline AST 05 & $02^{\circ} 25^{\prime} 17,20^{\prime \prime}$ & $54^{\circ} 41^{\prime} 53,60^{\prime}$, & $\begin{array}{l}\text { Ponto localizado na periferia de Santarém } \\
\text { próximo à Vila Arigó. }\end{array}$ \\
\hline AST 06 & $02^{\circ} 25^{\prime} 47,30^{\prime \prime}$ & $54^{\circ} 41^{\prime} 19,60^{\prime \prime}$ & $\begin{array}{l}\text { Ponto localizado na periferia de Santarém } \\
\text { próximo ao Bairro Uruará sujeito a despejos de } \\
\text { esgotos domésticos. }\end{array}$ \\
\hline AST 07 & $02^{\circ} 26^{\prime} 15,00^{\prime \prime}$ & $54^{\circ} 40^{\prime} 45,60^{\prime}$ & $\begin{array}{l}\text { Ponto localizado na periferia de Santarém } \\
\text { próximo à Foz do rio Maicá sujeito a despejos } \\
\text { de esgotos domésticos, industriais, lixões, } \\
\text { madeireira, matadouro, etc. }\end{array}$ \\
\hline
\end{tabular}

Tabela 2. Metodologia e equipamentos utilizados.

\begin{tabular}{|c|c|c|c|}
\hline Parâmetro & $\begin{array}{l}\text { Equipamento } \\
\text { marca/modelo }\end{array}$ & Método & Norma \\
\hline Turbidez & Orbeco-Hellige/966 & Nefelométrico & ASTM D 1889-81 \\
\hline $\mathrm{pH}$ & PHTEK/PH-100 & Potenciométrico & ASTM D 1293-78 \\
\hline Temperatura & Quimis/Q-408-P & Termômetro & - \\
\hline Oxigênio Dissolvido & Quimis/Q-408-P & Oxidimétrico & ASTM D 888-81 \\
\hline Alcalinidade & - & Titrimétrico & CETESB - L5.102 \\
\hline Elementos químicos & $\begin{array}{l}\text { ICP-AES Varian/Vista } \\
\text { pro }\end{array}$ & $\begin{array}{l}\text { Espectrometria de } \\
\text { emissão atômica }\end{array}$ & Varian \\
\hline Arsênio & $\begin{array}{l}\text { HG -ICP-AES } \\
\text { Varian/Vista pro }\end{array}$ & $\begin{array}{l}\text { Espectrometria de } \\
\text { emissão atômica com } \\
\text { geração de hidretos }\end{array}$ & Varian \\
\hline Mercúrio & $\begin{array}{l}\text { CVAAS } \\
\text { Varian/Spectra AA55 }\end{array}$ & $\begin{array}{l}\text { Espectrometria de } \\
\text { absorção atômica com } \\
\text { geração de vapor frio }\end{array}$ & Varian \\
\hline
\end{tabular}


A seleção dos comprimentos de ondas utilizados para cada elemento foi feita de forma a obter a maior altura dos picos e menor interferência espectral com o sinal de outros elementos. O controle de qualidade das determinações foi realizado pela análise de amostra de referência com certificado NIST/SRM-1640 (National Institute of Standards and Technology) de elementos traço em água natural, em que foi avaliada a exatidão, limite de detecção (LD) e limite de quantificação (LQ) dos métodos. Os resultados da recuperação dos elementos no padrão de referência de água de rio $(\mu \mathrm{g} / \mathrm{L})$ variaram de 86,98 a $112,65 \%$. Os limites de detecção e quantificação do instrumento foram determinados por meio da leitura de 15 brancos. O limite de detecção é definido como a menor quantidade de um analito que pode ser detectado em uma amostra. O limite de quantificação é a menor quantidade de um analito que pode ser quantitativamente determinada com adequada exatidão e precisão (Leite, 2002).

Os comprimentos de onda das linhas de emissão, os limites de detecção e quantificação para cada elemento, assim como os parâmetros da curva analítica coeficiente angular, linear e de correlação estão na tabela 3 , com valores de concentração em $\mu \mathrm{g} / \mathrm{L}$.

Os resultados obtidos na avaliação dos parâmetros físico-químicos e na análise dos elementos químicos foram tratados utilizando-se estatística descritiva e multivariada como ferramenta auxiliar e os programas Microsoft Office Excel 2007 e Statistica 7 no cálculo dos resultados. Os gráficos foram executados nos mesmos programas.

O rio Tapajós, no entorno da cidade de Santarém, foi classificado neste estudo como pertencente à classe 2 de acordo com a resolução 357-05 do CONAMA (Brasil, 2005), por abastecer cidades que fazem tratamento convencional na água do rio e populações ribeirinhas que não utilizam qualquer tratamento. Os valores encontrados para os parâmetros avaliados foram comparados com os valores limites estabelecidos nessa resolução.

Tabela 3. Parâmetros analíticos.

\begin{tabular}{ccccccc}
\hline Elementos & $\boldsymbol{\lambda}(\mathbf{n m})$ & $\mathbf{L D}(\boldsymbol{\mu g} / \mathbf{L})$ & $\mathbf{L Q}(\boldsymbol{\mu g} / \mathbf{L})$ & $\mathbf{a}$ & $\mathbf{b}$ & $\mathbf{R}$ \\
\hline $\mathrm{Al}$ & 308,22 & 2,07 & 6,88 & 4,18 & 184,10 & 0,9983 \\
$\mathrm{Ag}$ & 328,07 & 2,11 & 7,03 & 1,56 & 3,56 & 0,9989 \\
$\mathrm{As}$ & 193,70 & 0,54 & 1,81 & 0,004 & $-0,0003$ & 0,9999 \\
$\mathrm{Ba}$ & 233,53 & 0,76 & 2,54 & 46,93 & 173,63 & 0,9998 \\
$\mathrm{Be}$ & 313,04 & 1,98 & 6,60 & 8,98 & 12,99 & 0,9993 \\
$\mathrm{Ca}$ & 317,93 & 16,05 & 53,49 & 15655 & 374,18 & 0,9997 \\
$\mathrm{Cd}$ & 214,44 & 0,66 & 2,19 & 38,51 & 124,22 & 0,9990 \\
$\mathrm{Co}$ & 228,62 & 4,03 & 13,43 & 65,78 & 76,98 & 0,9991 \\
$\mathrm{Cr}$ & 267,72 & 0,87 & 2,90 & 17,99 & 60,54 & 0,9990 \\
$\mathrm{Cu}$ & 324,75 & 1,67 & 5,56 & 27,93 & 269,43 & 0,9983 \\
$\mathrm{Fe}$ & 238,86 & 4,77 & 15,91 & 3740 & 54,88 & 0,9998 \\
$\mathrm{Hg}$ & 253,70 & 0,23 & 0,77 & 0,007 & $-0,001$ & 0,9995 \\
$\mathrm{Mg}$ & 278,30 & 8,28 & 27,58 & 381,94 & 19,65 & 0,9999 \\
$\mathrm{Mn}$ & 257,61 & 1,20 & 4,00 & 158,45 & 419,88 & 0,9999 \\
$\mathrm{Mo}$ & 379,83 & 3,82 & 12,74 & 5,33 & 122,82 & 0,9973 \\
$\mathrm{Ni}$ & 231,60 & 4,22 & 14,06 & 5,07 & 2,659 & 0,9992 \\
$\mathrm{~Pb}$ & 220,35 & 9,68 & 32,25 & 2,59 & 42,22 & 0,9982 \\
$\mathrm{Sr}$ & 407,77 & 0,10 & 0,33 & 2510,4 & 10665 & 0,9992 \\
$\mathrm{Ti}$ & 334,94 & 1,30 & 4,33 & 24,31 & 397,5 & 0,9994 \\
$\mathrm{Zn}$ & 213,86 & 4,88 & 16,28 & 30,07 & 140,81 & 0,9996 \\
\hline
\end{tabular}




\section{RESULTADOS E DISCUSSÃO}

Todos os resultados aqui apresentados são médias obtidas das três profundidades (superficial, intermediário e fundo) e foram realizados em triplicata.

Os resultados obtidos para os parâmetros físico-químicos estão representados na tabela 4. Estão mostrados juntamente com os valores estabelecidos para alguns parâmetros pela resolução 357/05 do CONAMA. Os valores mostrados em negrito estão em não conformidade com a resolução.

Informações sobre diversos rios da Amazônia foram obtidas pelo HiBAm (Projeto Hidrologia da Bacia Amazônica) (Abdo et al., 1997), um projeto científico internacional envolvendo o Brasil, Equador, Bolívia e França para estudar a hidrologia e a geoquímica da Bacia Amazônica e foram usadas nas discussões por apresentarem resultados referentes ao rio Tapajós. Outros trabalhos como o de Pereira (2000) que avaliou os elementos ( $\mathrm{Al}, \mathrm{Cd}, \mathrm{Cr}, \mathrm{Cu}$, $\mathrm{Mn}, \mathrm{Ni}, \mathrm{Pb}, \mathrm{Zn}, \mathrm{As}$ ) na foz do rio Amazonas, incluindo os canais Norte (em frente a cidade de Macapá e Santana-AP), Sul (em frente as cidades de Afuá e Chaves na ilha do Marajó-PA) e no Rio Pará (de Breves a Belém-PA), foram usados com o objetivo de estabelecer parâmetros de referência quanto aos parâmetros físico-químicos e a presença dos elementos químicos em outros rios da Amazônia e compor as discussões apresentadas. Na tabela 5 se encontram alguns valores dos parâmetros físico-químicos obtidos em outros trabalhos realizados em rios da região amazônica.

Tabela 4. Resultados dos parâmetros físico-químicos nas águas do rio Tapajós.

\begin{tabular}{lccccc}
\hline \multicolumn{1}{c}{ Estações de coleta } & $\mathbf{p H}$ & $\begin{array}{c}\text { Temperatura } \\
\text { da água }\left({ }^{\circ} \mathbf{C}\right)\end{array}$ & $\begin{array}{c}\text { Oxigênio } \\
\text { dissolvido } \\
(\mathbf{m g} / \mathbf{L})\end{array}$ & $\begin{array}{c}\text { Turbidez } \\
(\mathbf{U N T})\end{array}$ & $\begin{array}{c}\text { Alcalinidade } \\
(\mathbf{m g} / \mathbf{L} \text { de CaCO }\end{array}$ \\
\hline CONAMA 357/05 & 6 a 9 & - & $>5$ & $<100$ & - \\
AST-01 & 7,8 & 29,6 & 6,1 & 72,0 & 15,8 \\
AST-02 & 7,6 & 29,6 & 6,1 & 80,0 & 9,5 \\
AST-03 & 7,8 & 29,8 & 6,0 & 70,0 & 9,5 \\
AST-04 & 6,7 & 29,6 & 6,0 & 75,0 & 9,5 \\
AST-05 & 7,8 & 29,8 & 6,0 & 75,0 & 7,4 \\
AST-06 & 7,8 & 29,8 & 5,8 & 85,0 & 7,4 \\
AST-07 & 6,6 & 29,6 & $\mathbf{4 , 5}$ & 78,0 & 9,5 \\
Média & 7,4 & 29,7 & 5,8 & 76,4 & 9,8 \\
Mediana & 7,8 & 29,6 & 6,0 & 75,0 & 9,5 \\
Desvio padrão & 0,6 & 0,1 & 0,6 & 5,1 & 2,8 \\
CV & 7,4 & 0,4 & 10,0 & 6,6 & 29,0 \\
Mínimo & 6,6 & 29,6 & 4,5 & 70,0 & 7,4 \\
Máximo & 7,8 & 29,8 & 6,1 & 85,0 & 15,8 \\
\hline
\end{tabular}

$\mathrm{CV}=$ Coeficiente de variação

O pH apresentou uma média de 7,44 e os valores mínimos foram encontrados no AST-07 e AST-04 (6,6 e 6,7, respectivamente), e o máximo de 7,8 nos demais pontos da coleta, esses valores mostram que o rio Tapajós antes do seu encontro com o rio Amazonas possui características levemente alcalinas e, após sua mistura, apresenta características de ácidas a levemente alcalinas, característica comuns em rios de águas brancas com pouca influência de ácidos húmicos (Sioli, 1957; Santos et al., 1985; Santos e Ribeiro, 1988; Konhauser et al., 1994; Dupré et al., 1996; Gaillardet et al., 1997). 
A comparação do pH deste estudo com as do HIBAM (Abdo et al., 1997) no rio Tapajós, estação Itaituba, (distante $250 \mathrm{~km}$ da foz do Tapajós), em outubro de 97 (final do período de estiagem), (S 04¹7'17"; W 05559'22"), mostrou que a média encontrada para o pH do rio Tapajós, no entorno da cidade de Santarém, está 1,16 vezes acima aos encontrados pelo HIBAM (Abdo et al., 1997) que encontrou uma média de pH de 6,7.

Tabela 5. Parâmetros físico-químicos nos rios da Amazônia.

\begin{tabular}{lccccc}
\hline Local & $\mathbf{p H}$ & $\mathbf{T}\left({ }^{\circ} \mathbf{C}\right)$ & $\begin{array}{c}\text { OD } \\
(\mathbf{m g} / \mathbf{L})\end{array}$ & Turbidez (UNT) & $\begin{array}{c}\text { Alcalinidade (mg/L de } \\
\left.\mathbf{C a C O}_{3}\right)\end{array}$ \\
\hline Canal Norte $^{\mathrm{a}}$ & 6,9 & 28,0 & - & - & - \\
Canal Sul $^{\mathrm{a}}$ & 6,5 & 26,0 & - & - & - \\
Rio Pará $^{\mathrm{a}}$ & 6,7 & 29,0 & - & - & - \\
Rio Negro $^{\mathrm{b}}$ & 5,0 & - & - & - & - \\
Rio Xingu $^{\mathrm{c}}$ & 7,3 & 28,8 & 5,5 & 2,5 & 10,9 \\
Rio Murucupi $^{\mathrm{d}}$ & 5,2 & 28,3 & 5,1 & 26,3 & 56,0 \\
Rio Tapajós $^{\mathrm{e}}$ & 6,7 & 32,2 & - & 6,5 & 6,9 \\
Rio Tapajós $^{\mathrm{f}}$ & 7,4 & 29,7 & 5,8 & 76,4 & 9,8 \\
\hline
\end{tabular}

${ }^{\mathrm{a}}\left(\right.$ Pereira, 2000); ${ }^{\mathrm{b}}$ (Küchler et al., 2000), ${ }^{\mathrm{c}}$ (Pereira et al., 2005); ${ }^{\mathrm{d}}$ (Pereira et al., 2007); ${ }^{\mathrm{e}}$ (Abdo et al., 1997); f(presente estudo)

As variações de $\mathrm{pH}$ podem ser devidas às descargas de efluentes domésticos e outros lançamentos, à influência das águas do rio Amazonas e outros fatores. No estudo das correlações, foram observadas excelentes correlações negativas entre $\mathrm{pH}$ e $\mathrm{Mn}(-0,8812)$ indicando que rochas que contém $\mathrm{Mn}$, quando intemperizadas podem estar liberando íons que combinados formam ácidos fracos, que causam a redução do $\mathrm{pH}$. Foram encontradas boas correlações positivas entre $\mathrm{pH}$ e temperatura $(0,6104)$, indicando neste estudo que as variações de temperatura estão diretamente relacionadas com as variações de $\mathrm{pH}$. Para Walker (1995), as variações no $\mathrm{pH}$ independem do regime pluviométrico em que as variações de temperatura são mais acentuadas. Também foram encontradas boas correlações positivas entre $\mathrm{pH}$ e oxigênio dissolvido $(0,6582)$, indicando que o OD influencia diretamente nas espécies formadoras de ácidos fracos.

A média da temperatura obtida foi de $29,7^{\circ} \mathrm{C}$, valor de acordo ao encontrado em outros rios da Amazônia, o valor médio encontrado está 1,1 vezes menor que o encontrado pelo HIBAM (Abdo et al., 1997) em Itaituba. A temperatura é uma variável que depende da hora da coleta e da estação sazonal, neste caso a temperatura medida pelo HIBAM (Abdo et al., 1997) no final do verão está coerente, pois esse é o período em que altas temperaturas são verificadas na região amazônica, diferentemente do período de maior precipitação (presente estudo) quando as temperaturas dificilmente ultrapassam $30^{\circ} \mathrm{C}$.

O oxigênio dissolvido apresentou uma média de $5,8 \mathrm{mg} / \mathrm{L}$ com uma variação de 4,5 a 6,1 $\mathrm{mg} / \mathrm{L}$ valores compatíveis com outros rios amazônicos. $\mathrm{O}$ valor mínimo apresentado se refere ao ponto AST-07, ponto localizado na periferia de Santarém, próximo à foz do rio Maicá sujeito a despejos de esgotos domésticos, industriais, lixões, madeireira, matadouro, etc. Essas atividades podem, eventualmente, causar impactos, tanto em águas superficiais quanto subterrâneas, decorrentes da grande produção de matéria orgânica associada às duas atividades e que causam a proliferação de micro-organismos que consomem o oxigênio. O próprio resíduo sólido oriundo dos lixões em contato direto com a água superficial poderá também causar a redução do OD (Chapman, 1992).

A adição de matéria orgânica nos cursos d'água consome oxigênio destes, pela oxidação química e, principalmente, da bioquímica, via respiração dos micro-organismos, depurando assim a matéria orgânica. Quando a carga dos esgotos lançados excede a capacidade de 
autodepuração do corpo de água, o rio fica sem oxigênio, provocando problemas estéticos e liberação de odor e impedindo a existência de peixes e outros seres aquáticos, os peixes morrem não por toxicidade, mas por asfixia. Todos os organismos vivos dependem de uma forma ou de outra do oxigênio para manter os processos metabólicos de produção de energia e de reprodução. A quantidade de alimento (esgoto ou outros despejos orgânicos assimiláveis) lançada ao corpo d'água deve ser proporcional à sua vazão ou ao seu volume, isto é, à sua disponibilidade de oxigênio dissolvido. Assim, a poluição orgânica de um curso d'água pode ser avaliada pelo decréscimo da concentração de oxigênio dissolvido e/ou pela concentração de matéria orgânica em termos de concentração de oxigênio necessário para oxidá-la (Valente et al., 1997).

O OD está inversamente associado aos metais $\mathrm{Al}, \mathrm{Ca}, \mathrm{Mg}, \mathrm{Sr}, \mathrm{Ba}$ e $\mathrm{Mn}$, pois foram observadas excelentes correlações negativas entre $\mathrm{OD}$ e $\mathrm{Al}(-0,8493)$, OD e $\mathrm{Ca}(-0,9667)$, OD e $\mathrm{Mg}(-0,9848)$ e OD e $\mathrm{Sr}(-0,9593)$ e boas correlações negativas entre o OD e Ba $(-0,6238)$ e OD e Mn (-0,7099). A influência de vários fatores torna as correlações enfraquecidas, a redução do oxigênio dissolvido, por exemplo, está condizente com o aumento do teor de ferro na água. A diminuição de oxigênio na água aumenta a tendência redutora do meio. Conforme o equilíbrio mostrado na equação: $2 \mathrm{Fe}^{2+}+1 / 2 \mathrm{O}_{2}+2 \mathrm{H}^{+} \Leftrightarrow 2 \mathrm{Fe}^{3+}+\mathrm{H}_{2} \mathrm{O}$.

A turbidez apresentou uma média de $76,4 \mathrm{mg} / \mathrm{L}$ com uma variação de 70 a 85 UNT. Os valores de turbidez obtidos demonstram que as águas do Tapajós, contêm sólidos em suspensão, um complexo coloidal composto de matéria orgânica, argila, colóide e silte e que sofrem a influência das águas do rio Amazonas já que na altura de Itaituba, onde o rio não sofre a influência das águas do rio Amazonas, a turbidez se encontra em termos de média com valor de 6,5 UNT (Abdo et al., 1997), turbidez característica de águas límpidas com pouco material em suspensão (Horbe et al., 2005).

A alcalinidade apresentou valores entre 7,55 e $15,75 \mathrm{mg} / \mathrm{L}$, com média de $9,75 \mathrm{mg} / \mathrm{L}$. A alcalinidade, encontrada no rio Tapajós, é devido aos bicarbonatos, já que não houve titulação até $\mathrm{pH} 8,3$ as alcalinidades relativas a hidróxidos, carbonatos não foram encontradas, a alcalinidade afeta diretamente o pH (Horbe et al., 2005). Esses valores estão coerentes com outros valores encontrados na Bacia Amazônica e estão 1,4 vezes acima do valor médio encontrado pelo HIBAM (Abdo et al., 1997). As variações encontradas podem ser devido às duas estações distintas: chuvosa (presente trabalho) e estiagem (Abdo et al., 1997), e/ou devido à proximidade dos pontos coletados ao rio Amazonas.

Para melhor visualização da variabilidade dos resultados, fez-se a divisão do boxplot geral dos parâmetros físico-químicos encontrados na água do Tapajós, que são mostrados na Figura 2.

O parâmetro que apresentou a maior variabilidade foi a turbidez com mediana em torno de 75 UNT e sem valores extremos ou anômalos, demonstrando a influência das águas do rio Amazonas nas águas do Tapajós. O pH com uma mediana em torno de 7,8 indica valores não anômalos às águas analisadas neste estudo. A temperatura apresenta valor mediano em torno de $29,60^{\circ} \mathrm{C}$, condizente com o período da realização da coleta em todos os pontos. O OD apresenta um valor extremo abaixo dos limites mínimos, devido ao baixo teor encontrado na estação AST-07 (4,5 mg/L), mas este não se constitui em um resultado anômalo, esses resultados não podem ser descartados. O resultado extremo, presente no parâmetro da alcalinidade com mediana em torno de $9,4 \mathrm{mg} / \mathrm{L}$ também não indica uma anomalia.

Os valores obtidos para os elementos químicos estão mostrados na tabela 6 . Os elementos: $\mathrm{Ag}(2,11 ; 10), \mathrm{Be}(1,98 ; 40), \mathrm{Cd}(0,66 ; 1), \mathrm{Co}(4,03 ; 50), \mathrm{Cr}(0,87 ; 50), \mathrm{Cu}(1,67$; 9), $\mathrm{Ni}(4,22 ; 25), \mathrm{Pb}(9,68 ; 10)$ e Zn $(4,88 ; 180)$ estiveram abaixo do limite de detecção (LD) da metodologia escolhida, entre parênteses estão os valores do $\mathrm{LD}$ e do valor limite do CONAMA 357-05 em $\mu \mathrm{g} / \mathrm{L}$. Como o LD desses elementos estão abaixo do máximo permitido pelo CONAMA, é possível afirmar que todos estiveram em conformidade com a resolução. 
MIRANDA, R. G.; PEREIRA, S. F. P.; ALVES, D. T. V.; OLIVEIRA, G. R. F. Qualidade dos recursos hídricos da Amazônia - Rio Tapajós: avaliação de caso em relação aos elementos químicos e parâmetros físico-químicos. Ambi-Agua, Taubaté, v. 4, n. 2, p. 75-92, 2009. (doi:10.4136/ambi-agua.88)

Na tabela 7, estão mostradas concentrações de alguns elementos em outros rios da Amazônia. De uma forma geral, os elementos $\mathrm{Cd}, \mathrm{Co}, \mathrm{Cr}, \mathrm{Cu}, \mathrm{Ni}$ e $\mathrm{Pb}$ se encontram em baixas concentrações em outros rios da Amazônia. O Zn se encontra em altas concentrações na foz do Amazonas e em baixas concentrações nos outros rios.

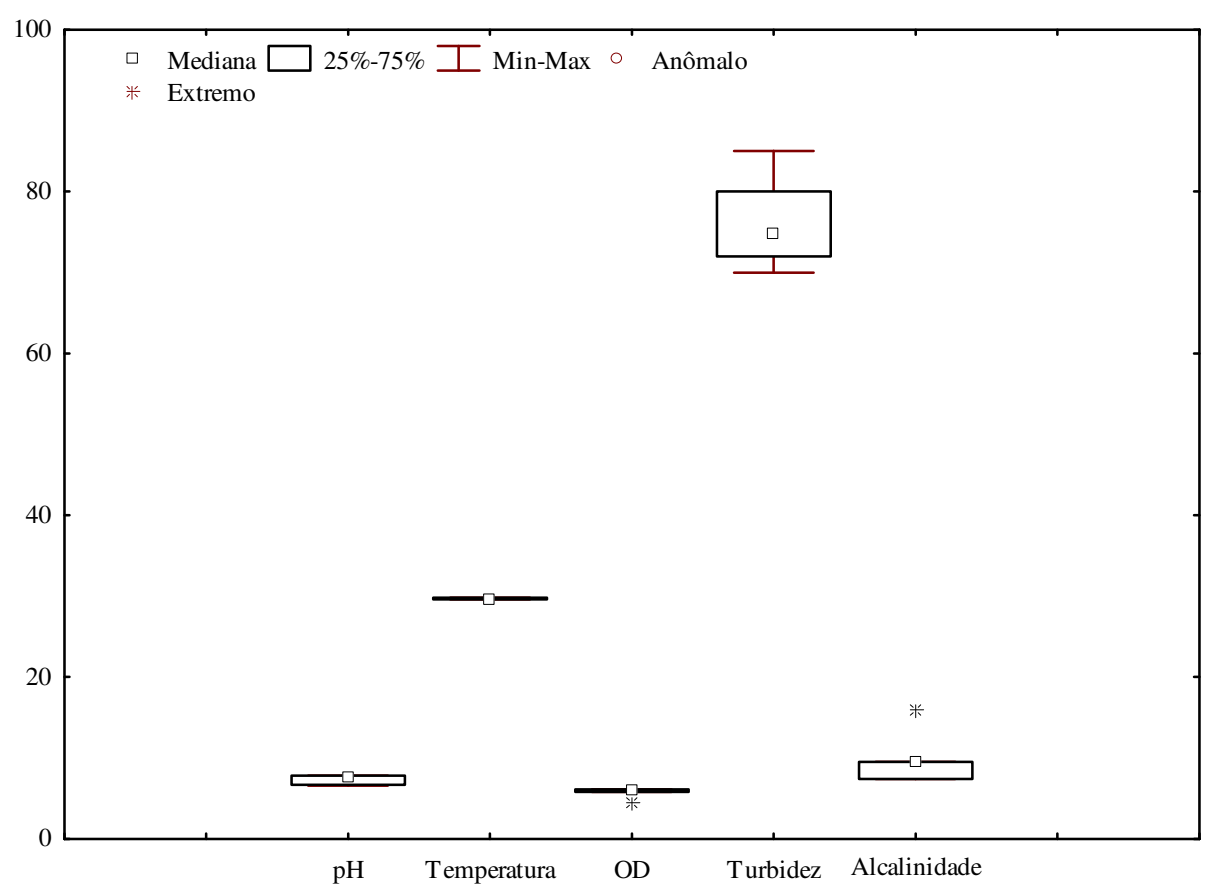

Figura 2. Boxplot dos parâmetros físico-químicos nas águas do rio Tapajós.

Tabela 6. Resultados dos elementos químicos nas águas do rio Tapajós $(\mu \mathrm{g} / \mathrm{L})$.

\begin{tabular}{lrrrrrrrr}
\hline Amostras & \multicolumn{1}{c}{ Fe } & \multicolumn{1}{c}{ Al } & \multicolumn{1}{c}{ Ba } & \multicolumn{1}{c}{ Mn } & \multicolumn{1}{c}{ Mg } & Ca & Sr & Ti \\
\hline CONAMA & 300,00 & 100,00 & 700,00 & 100,00 & - & - & - & - \\
357/05 & & & & - & & & - \\
AST-01 & $\mathbf{4 1 1 , 6 7}$ & 47,55 & 2,62 & 8,94 & 344,60 & 1050,90 & 9,13 & 4,75 \\
AST-02 & $\mathbf{8 0 2 , 4 3}$ & 68,63 & 1,47 & 8,43 & 339,76 & 1087,30 & 9,12 & 6,17 \\
AST-03 & $\mathbf{1 0 0 0 , 2 0}$ & 80,20 & 1,87 & 11,00 & 360,63 & 1170,50 & 9,65 & 7,07 \\
AST-04 & 227,81 & 83,57 & 4,01 & 18,99 & 261,18 & 211,12 & 2,89 & 1,82 \\
AST-05 & $\mathbf{6 0 7 , 2 8}$ & $\mathbf{3 2 2 , 4 8}$ & 0,00 & 2,20 & 266,77 & 210,22 & 3,00 & 18,88 \\
AST-06 & 113,63 & $\mathbf{5 6 9 , 5 2}$ & 2,74 & 11,67 & 502,16 & 893,67 & 8,38 & 7,08 \\
AST-07 & $\mathbf{7 9 1 , 1 9}$ & $\mathbf{7 8 8 , 1 4}$ & 4,62 & 22,95 & 1226,30 & 7066,00 & 42,57 & 11,79 \\
Média & $\mathbf{5 6 4 , 8 9}$ & $\mathbf{2 8 0 , 0 1}$ & 2,47 & 12,02 & 471,63 & 1669,96 & 12,11 & 8,22 \\
Mediana & $\mathbf{6 0 7 , 2 8}$ & 83,57 & 2,62 & 11,001 & 344,60 & 1050,90 & 9,12 & 7,07 \\
Desvio & 326,51 & 294,69 & 1,56 & 6,93 & 342,19 & 2413,54 & 13,75 & 5,57 \\
CV (\%) & 57,80 & 105,24 & 63,16 & 57,65 & 72,55 & 144,53 & 113,54 & 67,76 \\
Mínimo & 113,63 & 47,55 & 0,00 & 2,20 & 261,18 & 210,22 & 2,89 & 1,82 \\
Máximo & 1000,20 & 788,14 & 4,62 & 22,95 & 1226,30 & 7066,00 & 42,57 & 18,88 \\
\hline
\end{tabular}

$\mathrm{CV}=$ Coeficiente de variação

Normalmente, existe uma grande dificuldade analítica em se determinar baixos níveis de $\mathrm{Hg}$ em águas. A técnica do CVAAS não foi adequada para estabelecer os valores de concentração do $\mathrm{Hg}$ em água, que se encontrou em níveis abaixo de $0,23 \mu \mathrm{g} / \mathrm{L}$, neste caso não é possível afirmar que o $\mathrm{Hg}$ esteve em conformidade com a resolução já que o LD da técnica é 1,15 vezes maior que o valor máximo permitido $(0,20 \mu \mathrm{g} / \mathrm{L})$. Mesmo em baixas concentrações 
a presença de $\mathrm{Hg}$ em águas naturais é preocupante devido a sua propriedade de bioacumulação na biota e no homem. A poluição das águas por mercúrio está associada especialmente à possibilidade de metilação no meio ambiente de sua forma inorgânica $\mathrm{Hg}^{2+}$ por bactérias e à complexação com compostos orgânicos dissolvidos que possibilita a manutenção de concentrações relativamente elevadas na coluna d'água e acesso preferencial à biota. $\mathrm{O}$ mercúrio associado ao material particulado em suspensão tende a sedimentar, enquanto o mercúrio dissolvido encontra-se mais biodisponível e pode ser incorporado pela biota (Lacerda e Malm, 2008), esse fato pode explicar os baixos níveis de $\mathrm{Hg}$ encontrados no rio Tapajós. O processo de acumulação do mercúrio nas bacias hidrográficas está diretamente ligado à distribuição dos tipos de solos, os quais passam a agir como filtros naturais, retendo grande parte do mercúrio aportado com as águas das chuvas. A capacidade da fase sólida do solo de reter metais da fase aquosa é o mais importante processo que controla a disponibilidade do mercúrio nessa matriz. Esse processo de retenção pode ocorrer, principalmente, por mecanismo de troca catiônica, por adsorção ou complexação com a matéria orgânica. Entre esses mecanismos, têm-se destacado a adsorção e acumulação do mercúrio pelos oxi-hidróxidos de ferro e alumínio na coluna do solo de regiões tropicais (Roulet et al., 1998; Hylander et al., 2000 e Fadini e Jardim, 2000), entre estas, a amazônica, a qual é caracterizada pela dominância, na fração argila, desses compostos metálicos (Dematté, 1988).

Tabela 7. Concentração dos elementos químicos nos rios da Amazônia $(\mu \mathrm{g} / \mathrm{L})$.

\begin{tabular}{|c|c|c|c|c|c|c|c|c|c|c|}
\hline & $\mathrm{Fe}$ & $\mathrm{Al}$ & $\mathrm{Ba}$ & $\mathrm{Mn}$ & $\mathrm{Mg}$ & $\mathrm{Ca}$ & $\mathrm{Sr}$ & $\mathrm{Ti}$ & $\mathrm{Hg}$ & $\mathrm{Ag}$ \\
\hline Canal Norte $^{\mathrm{a}}$ & - & 1654,2 & - & - & - & - & - & - & - & - \\
\hline Canal Sul ${ }^{\mathrm{a}}$ & - & 208,6 & - & - & - & - & - & - & - & - \\
\hline Rio Paráa & - & 110,2 & - & 38,1 & - & - & - & - & - & - \\
\hline Rio Negro ${ }^{b}$ & 220,0 & 111,0 & 8,1 & 10,7 & 142,0 & 4200,0 & 4,8 & 0,48 & - & - \\
\hline 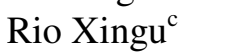 & 508,6 & 54,6 & 47,9 & 21,2 & 1299,0 & 4391,7 & 15,7 & - & - & - \\
\hline Rio Murucupi ${ }^{\mathrm{d}}$ & 1080,8 & 356,0 & 26,4 & 57,7 & 1249,8 & 3869,8 & 23,1 & - & - & - \\
\hline Rio Tapajós ${ }^{\mathrm{e}}$ & - & - & 18,5 & - & 680,0 & 1370,0 & 6,8 & - & - & - \\
\hline \multirow[t]{2}{*}{ Rio Tapajós $\mathrm{s}^{\mathrm{f}}$} & 564,9 & 280,0 & 2,5 & 12,0 & 471,6 & 1670,0 & 12,1 & 8,22 & $<0,23$ & $<2,11$ \\
\hline & As & $\mathrm{Be}$ & $\mathrm{Cd}$ & Co & $\mathrm{Cr}$ & $\mathrm{Cu}$ & $\mathrm{Ni}$ & $\mathrm{Pb}$ & $\mathrm{Zn}$ & Mo \\
\hline Canal Norte $^{\mathrm{a}}$ & 8,0 & - & 0,1 & - & 1,2 & 11,1 & 2,8 & 18,4 & 51,4 & - \\
\hline Canal Sul ${ }^{\mathrm{a}}$ & 12,0 & - & 0,2 & - & 2,5 & 7,6 & 2,9 & 2,2 & 151,1 & - \\
\hline Rio Paráa & 4,2 & - & - & - & - & 4,7 & - & 6,3 & 17,2 & - \\
\hline Rio Negro ${ }^{b}$ & 0,1 & - & - & 0,1 & 0,1 & 0,4 & 0,2 & 0,2 & 2,7 & - \\
\hline 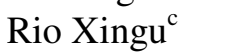 & 4,1 & - & - & - & 0,6 & 0,8 & 0,1 & 0,4 & 5,4 & - \\
\hline Rio Murucupi ${ }^{\mathrm{d}}$ & - & - & - & - & 0,4 & 2,5 & 2,4 & 2,8 & 13,3 & - \\
\hline Rio Tapajós ${ }^{\mathrm{e}}$ & - & - & - & 0,02 & 0,4 & 0,2 & 0,3 & - & 2,6 & 0,06 \\
\hline Rio Tapajós ${ }^{\mathrm{f}}$ & $<0,54$ & $<1,98$ & $<0,66$ & $<4,03$ & $<0,87$ & $<1,67$ & $<4,22$ & $<9,68$ & $<4,88$ & $<3,82$ \\
\hline
\end{tabular}

A técnica do HGICPAES também não foi recomendada para a análise do As $(1,88 \mu \mathrm{g} / \mathrm{L}$; $10 \mu \mathrm{g} / \mathrm{L}$ ) que apresentou valores abaixo do LD em todos os pontos avaliados. O elemento se mostrou em conformidade com a resolução do CONAMA e com valores de acordo com os valores encontrados nos rios da Amazônia.

$\mathrm{O}$ Mo $(\mathrm{LD}=3,82 \mu \mathrm{g} / \mathrm{L})$ não apresenta valor restritivo na resolução do CONAMA e de acordo com o valor encontrado pelo HIBAM (Abdo et al., 1997) haveria necessidade do uso de uma técnica que determinasse valores em torno de $0,06 \mu \mathrm{g} / \mathrm{L}$.

Os elementos $\mathrm{Mg}, \mathrm{Ca}$, $\mathrm{Sr}$ e Ti também não possuem valores restritivos na resolução do CONAMA, apresentando teores médios de 471,63 $\mu \mathrm{g} / \mathrm{L} ; 1669,96 \mu \mathrm{g} / \mathrm{L} ; 12,11 \mu \mathrm{g} / \mathrm{L}$ e 
$8,22 \mu \mathrm{g} / \mathrm{L}$, respectivamente. Nas águas naturais, não marinhas, o cálcio encontra-se de preferência na forma de íon $\mathrm{Ca}^{2+}$ e sua concentração basicamente é determinada pelo equilíbrio $\mathrm{CO}_{2}^{-}$e $\mathrm{CaCO}_{3}$. Em águas puras, a solubilidade do calcário é muito baixa (no máximo $15 \mathrm{mg} / \mathrm{L}$ ), porém ela aumenta rapidamente com a presença de $\mathrm{CO}_{2}$ dissolvido, até atingir o equilíbrio $\mathrm{CaCO}_{3}-\mathrm{H}_{2} \mathrm{OCO}_{2}$, nesse estágio a água não dissolve nem precipita carbonato de cálcio (Fenzl, 1986). Os elementos $\mathrm{Mg}$, Ca e Sr estão de acordo com a faixa de concentração encontrada em relação a outros rios da Amazônia. O Mg $(471,6 \mu \mathrm{g} / \mathrm{L})$ apresentou concentração média 1,44 vezes menor que os valores do projeto HIBAM $(680,0$ $\mu \mathrm{g} / \mathrm{L})$. O cálcio $(1669,96 \mu \mathrm{g} / \mathrm{L})$ apresentou-se 1,22 vezes maior que o do Projeto HIBAM $(1370,0 \mu \mathrm{g} / \mathrm{L})$.

Fenzl (1986) sugere que as concentrações de Ca e Mg são, aproximadamente, iguais em rochas dolomíticas, teoricamente o equilíbrio entre ambos só pode ser atingido depois de um período de contato suficientemente prolongado entre a água e a rocha (ou sedimento) de calcário. Outras excelentes correlações podem ter ocorrido devido atividades antropogênicas ou pelo intemperismo da época de coleta. São boas as correlações positivas encontradas entre Ca e Mn (0,6772), Mg e Mn (0,6864) e Sr e Mn (0,6684).

$\mathrm{O} \mathrm{Sr}$ apresentou concentração 1,78 vezes maior no presente estudo $(12,1 \mu \mathrm{g} / \mathrm{L})$ que no projeto HIBAM $(6,8 \mu \mathrm{g} / \mathrm{L})$. Neste estudo ficou comprovado o enriquecimento de $\mathrm{Ca}$ e $\mathrm{Sr}$ ao longo do rio Tapajós, esse comportamento pode ser explicado pela intensa lixiviação que ocorre em decorrência das chuvas no período de coleta. Destaca-se também a excelente correlação do cálcio com magnésio $(0,9819)$ e cálcio com estrôncio $(0,9989)$, que pode ser relacionada com a geoquímica da região.

O Ti apresentou concentração média 17,13 vezes acima da média de concentração encontrada para o rio Negro, o titânio se encontra associado com Al e Fe em vários minerais encontrados na região inclusive a bauxita. O maior nível de concentração do Ti foi na estação AST-05 (18,88 $\mu \mathrm{g} / \mathrm{L})$.

As maiores concentrações de Mn e Ba foram encontradas na estação AST-07 (22,95 $\mu \mathrm{g} / \mathrm{L}$ e 4,62 $\mu \mathrm{g} / \mathrm{L}$, respectivamente). Os elementos $\mathrm{Mn}$ e Ba possuem limitação na resolução do CONAMA e se mantiveram em níveis abaixo da resolução e de acordo com os níveis encontrados para outros rios da Amazônia. O magnésio apresentou-se 1,45 vezes menor $(0,47$ $\mu \mathrm{g} / \mathrm{L})$ que no projeto $\operatorname{HIBAM}(0,68 \mu \mathrm{g} / \mathrm{L})$. O Ba teve uma alta variação entre os dois estudos sendo 7,50 vezes menor no presente estudo $(2,47 \mu \mathrm{g} / \mathrm{L})$ que no projeto $\operatorname{HIBAM}(18,53 \mu \mathrm{g} / \mathrm{L})$. Foram observadas excelentes correlações positivas entre $\mathrm{Ba}$ e $\mathrm{Mn}(0,9597)$ e entre $\mathrm{Mg}$ e $\mathrm{Sr}$ (0,9825). São boas as correlações positivas encontradas entre $\mathrm{Ba}$ e $\mathrm{Ca}(0,6005)$ e $\mathrm{Ba}$ e $\mathrm{Mg}$ $(0,6230)$.

$\mathrm{O}$ Fe apresentou-se acima do permitido pelo CONAMA, para rios de classe 2, em quase todos os pontos tendo seu valor máximo encontrado no ponto AST-03 $(1000,20 \mu \mathrm{g} / \mathrm{L})$ e mesmo sua média $(564,89 \mu \mathrm{g} / \mathrm{L})$ está 1,88 vezes acima dos valores estabelecidos para esse elemento pela resolução CONAMA. Esses altos valores obtidos para o $\mathrm{Fe}$ podem ser explicados pela composição geoquímica da região onde o ferro apresenta mobilidade relativa regular. Em pH maior que 4,8 é comum encontrar-se maior quantidade de ferro nas formas de hidróxidos e óxidos (Mazzeo, 1991). Em relação a outros rios da Amazônia (220,0 a 1080,8 $\mu \mathrm{g} / \mathrm{L})$, o Fe, embora com valores elevados em relação à resolução do CONAMA, está com níveis considerados normais para a região.

$\mathrm{O} \mathrm{Al}$ apresentou-se 2,80 vezes acima dos níveis permitidos pelo CONAMA em termos de média $(280,01 \mu \mathrm{g} / \mathrm{L})$ e em três estações, sendo seus valores até 3,22 (AST-05); 5,69 (AST-06) e 7,88 (AST-07) vezes maiores que o permitido pelo CONAMA. O Al está em concentrações condizentes com outros rios da Amazônia $(54,6 \mu \mathrm{g} / \mathrm{L}$ a $1654,2 \mu \mathrm{g} / \mathrm{L})$ e se encontra em não conformidade com a resolução do CONAMA, estando 2,8 vezes acima do nível máximo 
considerado pela resolução. Vários metais traços podem ser responsáveis por agravos às doenças neurológicas, sendo o $\mathrm{Al}$ um metal estudado com relação ao mal de Alzheimer e esclerose, do mesmo modo existe uma discussão sobre a influência do $\mathrm{Mn}, \mathrm{Fe}$ e $\mathrm{Cu}$ sobre o mal de Parkinson (Brown et al., 2005). Esse elemento provoca a contaminação de solo, impedindo o desenvolvimento de plantas (Pereira e Reis, 2002). Para o rio Tapajós, não foi encontrada referência ao elemento no projeto HIBAM (Abdo et al., 1997).

O comportamento do alumínio no ambiente depende de como se encontra e das características do meio, complexa-se com moléculas de água, ânions cloretos, sulfatos, nitratos, fosfatos e material húmico. A concentração de íons alumínio em águas naturais normalmente é pequena, tipicamente $27 \mu \mathrm{g} / \mathrm{L}$. Esse baixo valor se deve ao fato de que em $\mathrm{pH}$ médio, de 6 a 9, das águas naturais a solubilidade do alumínio, contido nas rochas e solos ao qual a água é exposta, é muito pequena, no caso do rio Tapajós onde o alumínio se encontra em altas concentrações, mesmo com pH médio pode-se pensar em uma contribuição antrópica do elemento, principalmente devido à mineração. A solubilidade do alumínio em águas é controlada pela solubilidade do $\mathrm{Al}(\mathrm{OH})_{3}$, segundo a equação: $\mathrm{Al}(\mathrm{OH})_{3(\mathrm{~s})} \Leftrightarrow \mathrm{Al}^{+3}+3 \mathrm{OH}^{-}$, percebe-se que a diminuição do $\mathrm{pH}$ das águas naturais provoca um aumento da concentração de íons alumínio na água (Baird, 1999).

$\mathrm{O}$ Al normalmente apresenta-se ligado a argilo-minerais em suspensão, oriundos de processos de intemperismo de rochas, como o mineral caulinita, tido como o principal contribuinte de alumínio na região amazônica. A um $\mathrm{pH}$ maior que 5,5, ocorre predominantemente na forma insolúvel ou como aluminossilicato (WHO, 1997). Esse é um constituinte maior e não reativo dos argilo-minerais (Sholkovitz e Price, 1980). A água é o principal agente do intemperismo químico, sendo um excelente solvente para todos os minerais com algumas exceções (Riley e Chester, 1989).

No estudo das correlações (Pearson), foram observadas excelentes correlações positivas ( $\mathrm{r}>0,8)$ entre $\mathrm{Al}$ e $\mathrm{Mg}(0,8339)$. São boas as correlações positivas encontradas entre o $\mathrm{Al}$ e $\mathrm{Ca}(0,7284)$ e $\mathrm{Al}$ e $\mathrm{Sr}(0,7258)$.

Para melhor visualização da locação e dispersão dos resultados fez-se a divisão dos elementos em dois grupos distintos por grandeza de concentração $(\mu \mathrm{g} / \mathrm{L})$, estes são mostrados nas Figuras 3 e 4.

Pela Figura 3 foi possível observar que, dentre os elementos maiores, o elemento que apresentou a maior variabilidade foi o $\mathrm{Ca}$ com um valor extremo $(7066,00 \mu \mathrm{g} / \mathrm{L})$ no ponto AST-07 (ponto com maior problema de lançamento de efluentes) e sem valores anômalos. Al e Fe se fizeram presentes sem muita variabilidade e sem resultados anômalos ou extremos. $\mathrm{O}$ $\mathrm{Mg}$ foi o elemento de menor variabilidade e apresentou um valor extremo $(1226,3 \mu \mathrm{g} / \mathrm{L})$ também no ponto AST-07. Os valores mínimos apresentados pelos elementos $\mathrm{Al}, \mathrm{Mg}$ e Ca e os valores máximos dos elementos $\mathrm{Mg}$ e Ca estão inseridos dentro da caixa que representa 25 a $75 \%$ dos resultados considerados normais para os elementos.

No grupo dos elementos menores apresentado na Figura 4, o que apresentou a maior variabilidade foi o $\mathrm{Mn}$ sem valores extremos ou anômalos. $\mathrm{O} \mathrm{Sr}$ apresentou um valor extremo $(42,57 \mu \mathrm{g} / \mathrm{L})$ no ponto AST-07. Ti não apresentou resultados anômalos nem extremos e o Ba foi o elemento com a menor variabilidade neste grupo sem resultados anômalos e extremos. $\mathrm{O}$ valor máximo do elemento $\mathrm{Sr}$ está inserido dentro da caixa que representa 25 a $75 \%$ dos resultados normais para o elemento. 
MIRANDA, R. G.; PEREIRA, S. F. P.; ALVES, D. T. V.; OLIVEIRA, G. R. F. Qualidade dos recursos hídricos da Amazônia - Rio Tapajós: avaliação de caso em relação aos elementos químicos e parâmetros físico-químicos. Ambi-Agua, Taubaté, v. 4, n. 2, p. 75-92, 2009. (doi:10.4136/ambi-agua.88)

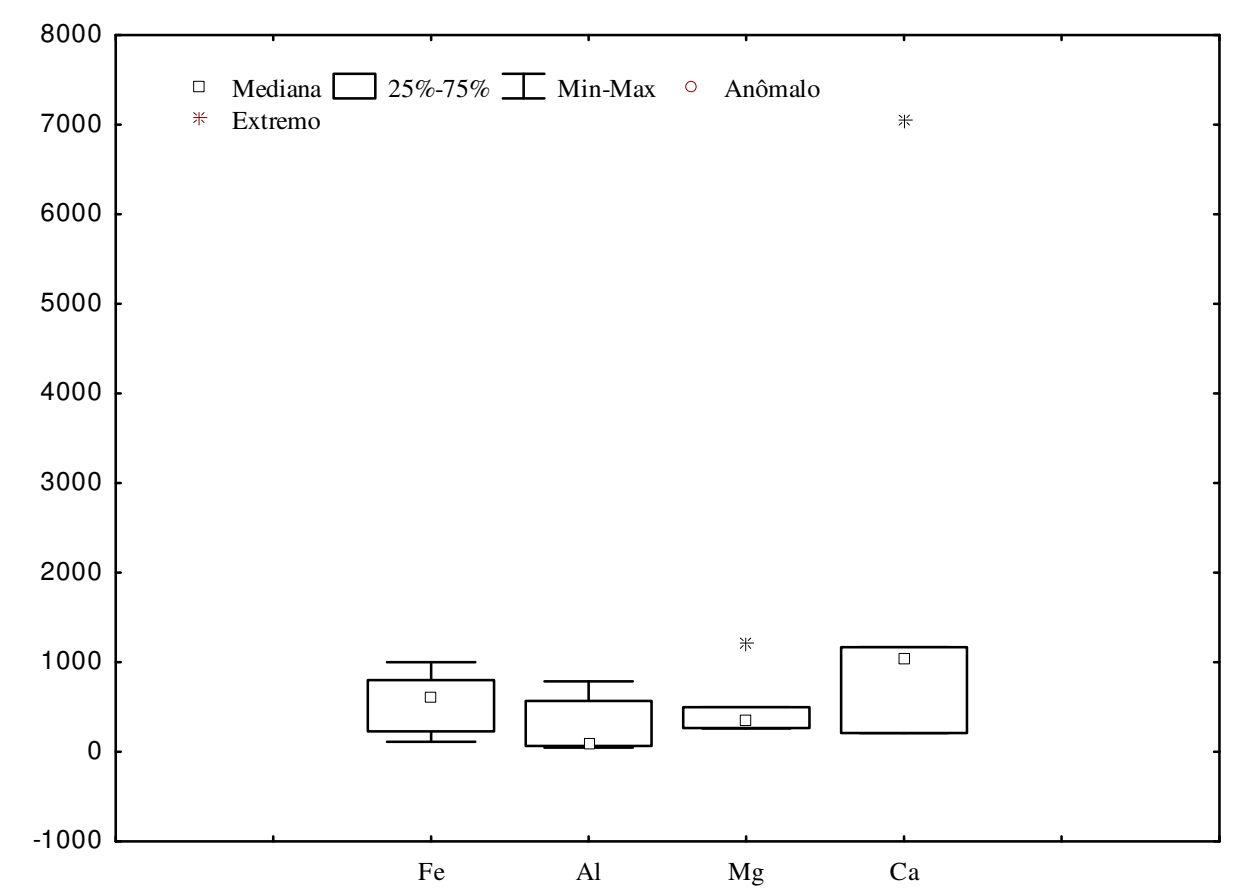

Figura 3. Boxplot dos elementos $\mathrm{Fe}, \mathrm{Al}, \mathrm{Mg}$ e Ca nas águas do rio Tapajós.

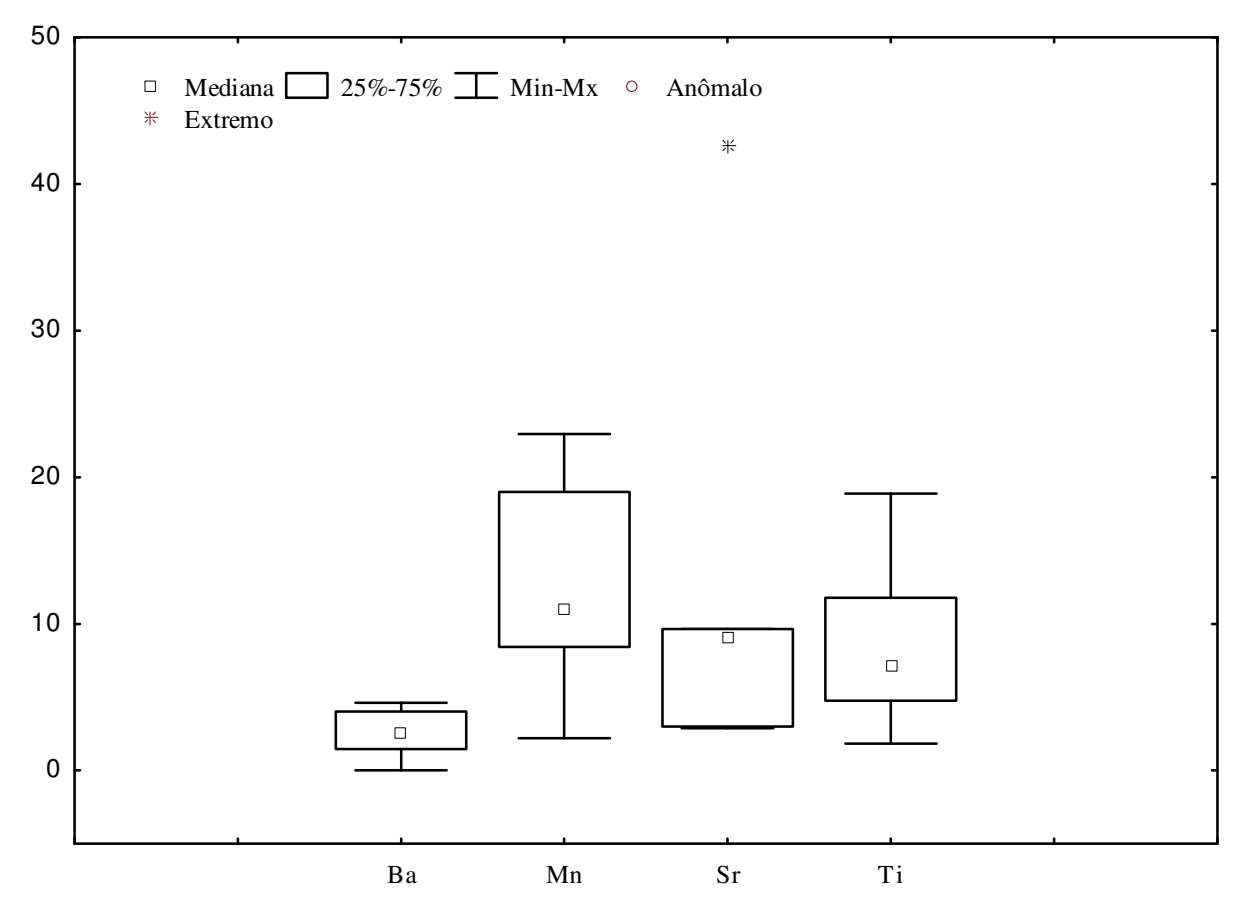

Figura 4. Boxplot dos elementos Ba, Mn, Sr e Ti nas águas do rio Tapajós.

\section{CONCLUSÃO}

A partir do levantamento realizado se verificou que os parâmetros físico-químicos analisados (pH, OD e turbidez) estão de acordo com a resolução do CONAMA, apenas o oxigênio dissolvido na estação AST-07 se encontra em não conformidade, caracterizando os efeitos da poluição das águas por dejetos orgânicos neste ponto. Acredita-se também que essas alterações se devem às instalações de logradouros públicos (matadouros e lixões) próximos ao rio Maicá. Segundo relato de moradores do bairro Diamantino e Maicá, as águas utilizadas por esses logradouros são despejadas diretamente no Maicá, e este pelo seu curso normal deságua no Tapajós. O problema tende a se agravar com o aumento da população local já que a cidade 
não conta com tratamento de esgoto e todo efluente doméstico e industrial é lançado, na orla de Santarém, onde foram localizados 90 canais de esgoto, despejando diariamente efluentes no rio Tapajós.

O rio Amazonas tem papel fundamental na alteração das características do rio Tapajós na sua foz, no entorno da cidade de Santarém e funciona como agente depurador tendo em vista o grande volume de suas águas neste trecho do rio.

As altas concentrações de ferro e alumínio encontradas no rio Tapajós podem ser explicadas devido à presença desses elementos nas rochas da região amazônica rica nesses dois elementos que quando são intemperizadas resultam em elementos químicos, nas formas de íons monoatômicos e íons poliatômicos e agregados em estruturas cristalinas tais como micas, feldspatos, argilominerais, quartzo, etc. Nessas condições os elementos são transportados para outros rios até chegar aos oceanos. Os metais $\mathrm{Al}$ e Fe em excesso na água do rio Tapajós podem acarretar problemas à saúde da população que se utiliza dessa água para consumo. Sugere-se um monitoramento constante das águas do rio estudado para prevenir o despejo indiscriminado dos resíduos sólidos e líquidos e a consequente contaminação dos recursos hídricos pelos elementos tóxicos.

\section{AGRADECIMENTOS}

Agradecemos aos alunos Ana Araújo Costa, Maria Eliete de Araújo Pinto e Ostene Carlos Nogueira Costa pela ajuda nas coletas in situ e ao apoio da Eletronorte.

\section{REFERÊNCIAS}

ABDO, J. M. M.; BENEVIDES, V. F. de S.; COIMBRA, R. M.; OLIVEIRA, E. de; LOURD, M.; FRITSCH, J. M. HIBAM: Hidrologia da Bacia Amazônica: décima campanha de amostragem de água e sedimentos nas bacias dos rios Tocantins, Xingu e Tapajós, Brasília, Marabá, Altamira, Itaituba. 1997. Disponível em: <www.ana.gov.br/hibam>. Acesso em: 01 jan. 2009.

AKAGI, H.; MALM, O.; BRANCHES, F. J. P.; KINJO, Y.; GUIMARÃES, J. R. D.; OLIVEIRA, R. B.; HARAGUCHI, K.; PFEIFFER, W. C.; TAKIZAWA, Y.; KATO, H. Human exposure to mercury due to goldmining in the Tapajos River Basin, Amazon, Brasil: speciation of mercury in hair, blood and urine. Water, Air and Soil Pollution, v. 80, p. 85-94, 1995.

BAIRD, C. Environmental Chemistry. 2. ed. Ontario: University of Western Ontario, 1999. $557 \mathrm{p}$.

BRASIL. Ministério do Meio Ambiente, Conselho Nacional do Meio Ambiente-CONAMA, Resolução $\mathbf{N}^{\mathbf{0}}$ 357, de 17 de março de 2005. Dispõe sobre a classificação dos corpos de água e diretrizes ambientais para o seu enquadramento,bem como estabelece as condições e padrões de lançamento de efluentes, e dá outras providências. Brasília: Gráfica e Editora Itamarati, 2005.

BROWN, R.; LOCKWOOD, A. H.; SONAWANE, B. R. Neurodegenerative diseases: an overview of environmental risk factors. Environmental Health Perspectives, Washington, v. 113, n. 9, p. 1250-1256, 2005.

COMPANHIA DE TECNOLOGIA DE SANEAMENTO AMBIENTAL CETESB - Guia de coleta e preservação de amostras de água. São Paulo: CETESB, 1987. 155p. 
CHALMERS, A. T.; VAN METRE, P. C.; CALLENDER, E. The chemical response of particle-associated contaminants in aquatic sediments to urbanization in New England, U.S.A., Journal of Contaminant Hydrology, Available online, v. 91, n. 1-2, p. 4-25, 2007.

CHAPMAN, D. Selection of water quality variables. In: Water quality assessments: a guide to the use of biota, sediments and water in environmental monitoring. 2. ed. London: $\mathrm{E}$ \& FN Spon, 1992. 605p.

DEMATTÉ, J. L. I. Manejos de solos ácidos dos trópicos úmidos, região Amazônica. Campinas: Fundação Cargill, 1988. 215p

DUPRÉ, B.; GAILLARDET, J.; ROUSSEAU, D.; ALLÉGRE, J. Major and trace elements of river-borned material: the Congo Basin. Geochimica et Cosmochimica Acta, v. 60 p. 1301-1321, 1996.

FADINI, P. S.; JARDIM, W. F. Dissolved gaseous mercury (DGM) fluxes in Negro River basin, Brazilian Amazon. In: INTERNATIONAL CONFERENCE ON HEAVY METALS IN THE ENVIRONMENT, 11., 6-10 August 2000, Ann Arbor. Proceedings... Ann Arbor: University of Michigan, School of Public Health, 2000. (1 CD-ROM)

FENZL, N. Introdução a hidrogeoquímica. Belém: Universidade Federal do Pará, 1986, 189 p.

FÖRSTNER, U.; WITTMANN, G. T. W. Metal pollution in the aquatic environment. Berlin: Springer-Verlag, 1983. p. 486.

GAILlARDET, J.; DUPRÉ, B.; ALlÉGRE, J.; NÉGREL, P. Chemical and physical denudation in the Amazon river basin. Chemical Geology, v. 142, p. 141-173, 1997.

GÖBEL, P.; DIERKES, C.; COLDEWEY, W. G.; J. Storm water runoff concentration matrix for urban areas. Journal of Contaminant Hydrology, v. 91, n. 1-2, p. 26-42, 2007.

HADLICH, G. M. e SCHEIBE, L. F. Dinâmica físico-química de águas superficiais em região de intensa criação de suínos: exemplo da bacia hidrográfica do rio Coruja-Bonito, município de Braço do Norte, SC. Geochimica Brasiliensis, v. 21, n. 3, p. 245 - 260, 2007.

HARADA, H.; HAKANISH, J.; YASODA, E.; PINHEIRO, M. C. N.; OIKAWA, T.; GUIMARÃES, G. A.; CARDOSO, B.; KIZAKI, T.; OHNO, H. Mercury pollution in the Tapajós river basin, Amazon. Mercury level of head hair aind health effects. Environmental International, v. 27, p. 285-290, 2001.

HORBE, A. M. C.; GOMES, I. L. F.; MIRANDA, S. F.; SILVA, M. S. R. Contribuição à hidroquímica de drenagens no Município de Manaus - AM. Acta Amazonica, v. 35, n. 2, p. 119-124. 2005.

HYLANDER, L. D.; MEILI, M.; OLIVEIRA, L. J.; SILVA, E. C.; GUIMARÃES, J. R. D.; ARAUJO, D. M.; NEVES, R. P.; STACHIW, R.; BARROS, A. J. P.; SILVA, G. D. Relationship of mercury with aluminum, iron and manganese oxy-hydroxides in sediments from the Alto Pantanal, Brazil. Science of the Total Environment, v. 260, p. 97-107, 2000. 
MIRANDA, R. G.; PEREIRA, S. F. P.; ALVES, D. T. V.; OLIVEIRA, G. R. F. Qualidade dos recursos hídricos da Amazônia - Rio Tapajós: avaliação de caso em relação aos elementos químicos e parâmetros físico-químicos. Ambi-Agua, Taubaté, v. 4, n. 2, p. 75-92, 2009. (doi:10.4136/ambi-agua.88)

INSTITUTO BRASILEIRO DE GEOGRAFIA E ESTATÍSTICA - IBGE. Dados da população do município de Santarém-PA. Disponível em: <http://www.ibge.gov.br/cidadesat/ topwindow.htm?1>. Acesso em: 11 fev. 2009.

KONHAUSER, K. O.; FYFE, W. S.; KRONBERG, B. I. Multi-element chemistry of some Amazonian waters and soils. Chemical Geology, v. 111, p. 155-175. 1994.

KÜCHLER, I. L.; MIEKELEY, N.; FORSBERG, B. R. A Contribution to the Chemical Characterization of Rivers in the Rio Negro Basin, Brazil. Journal of the Brazilian Chemical Society, v. 11, n. 3, p. 286-292, 2000.

LACERDA, L. D.; SALOMONS, W. Mercury from Gold and Silver Mining: a chemical time bomb? Berlim: Springer-Verlag, 1998. 146p.

LACERDA, L. D. de; MALM, O. Contaminação por mercúrio em ecossistemas aquáticos: uma análise das áreas críticas. Estudos Avançados, São Paulo, v. 22, n. 63, p. 173 190, 2008.

LEITE, F. Validação em análise química. 4. ed. Campinas: Átomo, 2002. 278p.

MALM, O. Gold Mining as a Source of Mercury Exposure in the Brazilian Amazon. Environmental Research, v. 77, n. 2, p. 73-78, 1998.

MALM, O.; PFEIFFER, W. C.; SOUZA, C. M. M.; REUTHER, R. Mercury pollution due to gold mining in the Madeira River Basin, Brazil. Ambio, v. 19, n. 1, p. 11-15, 1990.

MARQUES, M. N.; COTRIM, M. B.; PIRES, M. A. F. Avaliação do impacto da agricultura em áreas de proteção ambiental, pertencentes à bacia hidrográfica do rio Ribeira de Iguape, São Paulo. Química Nova, São Paulo, v. 30, n. 5, p. 1171-1178, 2007.

MAZZEO, T. E. Avaliação ambiental dos rios de drenagem da região metropolitana de Belém - PA: quanto a distribuição dos elementos $\mathrm{Ca}, \mathrm{Cd}, \mathrm{Cr}, \mathrm{Cu}, \mathrm{Fe}, \mathrm{Hg}, \mathrm{K}, \mathrm{Mg}, \mathrm{Mn}$, $\mathrm{Na}, \mathrm{Ni}, \mathrm{Pb}$ e Zn. 1991. 141f. Dissertação (Mestrado em Geociências) - Universidade Federal do Pará, Belém, 1991.

NRIAGU, J. O. Legacy of mercury pollution. Nature, v. 363, n. 6430, p. 589-589, 1992.

PEREIRA, M. do S. S.; REIS, B. F. dos. Determinação espectrofotométrica de alumínio em concentrados salinos utilizados em hemodiálise empregando pré-concentração em fluxo. Química Nova, São Paulo, v. 25, n. 6, p. 931-934, 2002.

PEREIRA, S. F. P; SARAIVA, A. F.; SIQUEIRA, G. W.; FREITAS, K. H.; LIMA, M. A. Avaliação de teores de elementos traço nas águas do rio Xingu - Região impactada pela garimpagem de ouro. Revista Traços, Belém, v. 7, n. 16, p. 53-60, 2005.

PEREIRA, S. F. P.; LIMA, M. A.; FREITAS, K. H.; MESCOUTO, C. S.; SARAIVA, A. F. Estudo químico ambiental do rio Murucupi - Barcarena, PA, Brasil, área impactada pela produção de alumínio. Revista Ambi-Água, Taubaté, v. 2, n. 3, p. 62-82, 2007.

PEREIRA, S. F. P. Avaliação da contaminação por metais pesados no Delta do Rio Amazonas. Belém: LAQUANAM - UFPA, 2000. 44 p.

PFEIFFER, W. C.; LACERDA, L. D. Mercury Imputs into the Amazon Region, Brazil. Environmental Technology Letters, v. 9, p. 325-330, 1988. 
RODRIGUES, R. M.; MASCARENHAS, A. F. S.; ICHIARA, A. H.; SOUZA, T. M. C.; BIDONE, E. D.; BELLIA, V. et al. Estudo dos impactos ambientais decorrentes do extrativismo mineral e poluição mercurial no Tapajós - pré-diagnóstico. Rio de Janeiro: CETEM/CNPq, 1994. p. 220. (Série Tecnologia Ambiental)

ROULET, M.; LUCOTTE, M.; SAINT-AUBIN, A.; TRAN, S.; RHÉAULT, I.; FARELLA, $\mathrm{N}$. et al. The geochemistry of mercury in central Amazonian soils developed on the Alter-do-Chao formation of the lower Tapajos River Valley, Para state, Brazil. Science of the Total Environment, v. 223, n. 1, p. 1-24, 1998.

ROULET, M.; LUCOTTE, M.; RHEAULT, I.; GUIMARÃES, J. R. D. Methylmercury in the water, seston and epiphyton of an Amazonian River and its floodplain, Tapajós River, Brazil. Science of the Total Environment, Amsterdam, v. 261, p. 43-59, 2000.

RILEY, J. P.; CHESTER, R. Introducción a la química marina. México: A.G.T., 1989. $457 \mathrm{p}$.

SA, A. L.; HERCULANO, A. M.; PINHEIRO, M. C.; SILVEIRA, L. C. L.; NASCIMENTO, J. L. M.; CRESPO-LÓPEZ, M. E. Human exposure to mercury in the west region of State of Pará. Revista Paraense de Medicina, v. 20, n. 1, p. 19-25, 2006.

SANTOS, U. M.; BRINGEL, S. R. B.; RIBEIRO, M. N. G.; SILVA, M. N. P. Rios da Bacia Amazônica II: os afluentes do rio Branco. Acta Amazonica, v. 15, p. 147-156, 1985.

SANTOS, U. M.; RIBEIRO, M. N. G. A hidroquímica do rio Solimões-AM. Acta Amazonica, v. 18, n. 3-4, p. 145-172, 1988.

SIOLI, H. Valores de pH de águas Amazônicas. Boletim do Museu Paraense Emilio Goeldi. Geologia, v. 1, p. 1-35. 1957.

SEYLER, P. T.; BOAVENTURA, G. R. Trace elements in the mainstem Amazon River, in the biogeochemistry of the Amazon Basin. In: MCCLAIN, M. E.; VICTORIA, F. R. L.; RICHEY, J. E. The Biogeochemistry of the Amazon basin and its Role in a Changing World. Oxford: Oxford Univ. Press, 2001. p. 307-327.

SHOLKOVITIZ, E. R.; PRICE, N. B. The major element of suspended matter in Amazon Estuary. Geochimica Cosmochimica Acta, v. 44, n. 2, p. 163-171, 1980.

VALENTE, J. P. S.; PADILHA, P. M.; SILVA, A. M. M. da. Oxigênio dissolvido (OD), demanda bioquímica de oxigênio (DBO) e demanda química de oxigênio (DQO) como parâmetros de poluição no ribeirão Lavapés/Botucatu - SP. Eclética Química, São Paulo, v. 22, p. 49-66, 1997.

WALKER, I. Amazonian streams and small rivers. In: TUNDISI, J. G.; BICUDO, C. E. M.; MATSUMURA TUNDISI, T. (Eds.) Limnology in Brazil. Rio de Janeiro: Brazilian Academy of Science, 1995. p.167-193.

WORLD HEALTH ORGANIZATION - WHO. Aluminium. Environmental Health Criteria, Geneva, v. 194, 1997.

ZIMMERMANN, C. M.; GUIMARÃES, O. M.; PERALTA-ZAMORA, P. G. Avaliação da qualidade do corpo hídrico do rio Tibagi na região de Ponta Grossa utilizando análise de componentes principais (PCA). Química Nova, Ponta Grossa, v. 31, n. 7, p. 1727-1732, 2008 . 